\title{
Formulation development and evaluation of transdermal patch of piroxicam for treating dysmenorrhoea
}

\author{
Nilesh M. Mahajan ${ }^{1 *}$, Grishma H. Zode' ${ }^{1}$, Debarshi Kar Mahapatra ${ }^{2}$, Sonali Thakre', Nitin Dumore ${ }^{3}$, Purushottam S. Gangane \\ ${ }^{1}$ Department of Pharmaceutics, Dadasaheb Balpande College of Pharmacy, Nagpur, India. \\ ${ }^{2}$ Department of Pharmaceutical Chemistry, Dadasaheb Balpande College of Pharmacy, Nagpur, India. \\ ${ }^{3}$ Department of Pharmacology, Dadasaheb Balpande College of Diploma in Pharmacy, Nagpur, India.
}

\begin{tabular}{l}
\hline ARTICLE INFO \\
\hline Received on: $25 / 05 / 2018$ \\
Accepted on: 08/10/2018 \\
Available online: $30 / 11 / 2018$ \\
\\
\hline Key words: \\
Dysmenorrhea, piroxicam, \\
transdermal, patch, NSAID, \\
sustained.
\end{tabular}

\begin{abstract}
Dysmenorrhea (pain with menstruation) affects up to $90 \%$ of adolescent and young women. Despite the availability of a variety of effective pharmacological treatments, it is frequently left untreated. Non-steroidal anti-inflammatory drugs (NSAIDs) are the best-established initial therapy for dysmenorrhoea. When NSAIDs are given through the oral route, it causes several side-effects like gastric disturbance, stomach ulcer, nausea, vomiting, etc. Piroxicam is an NSAID utilized for treating dysmenorrhoea in the form of tablet formulation. As mentioned above, it also suffers from similar adverse effects. To overcome those conditions, the transdermal patch of piroxicam can serve as a better alternative to the tablets which serves as the safe alternative over oral route. In the present research, the transdermal patch of piroxicam was fabricated by using sustained release hydrophilic and lipophilic polymers containing permeation enhancer and thoroughly evaluated. The transdermal patches of piroxicam were prepared using the combination of polymers, hydroxypropyl methylcellulose E15, polyvinylpyrrolidone (PVP) K30, and ethyl cellulose in different concentration with sodium lauryl sulfate as the permeation enhancer and polyethylene glycol 400 as the plasticizer was used for the formulation of transdermal drug delivery system which demonstrated sustained release of the drug through the patches. The formulation F1 containing hydrophilic and lipophilic polymers (3:1 ratio) showed the maximum release and permeation of drug for a longer time period up to 12 hours which made it suitable for the development of sustained release patches of piroxicam.
\end{abstract}

\section{INTRODUCTION}

Dysmenorrhea (pain with menstruation) affects up to $90 \%$ of adolescent and young women. Despite the availability of a variety of effective pharmacological treatments, it is frequently left untreated (Brunton et al., 2008). The pathogeneses behind the symptoms are largely unknown but increased uterine contractions, uterine vasoconstriction, and/or myometrial re-innervation following uterine injury have been proposed (Kumar et al., 1992). Primary dysmenorrhea is the painful menses in women with normal pelvic anatomy, begins during adolescence, characterized by crampy pelvic pain which

\section{*Corresponding Author}

Nilesh M. Mahajan, Department of Pharmaceutics, Dadasaheb Balpande College of Pharmacy, Nagpur, India.E-mail:nmmahajan78@gmail.com begins shortly before or at the onset of menses and lasting 1-3 days (Colledge et al., 2010).

Non-steroidal anti-inflammatory drugs (NSAIDs) are the best-established initial therapy for dysmenorrhoea. They have a direct analgesic effect through the inhibition of prostaglandin synthesis and they also decrease the volume of menstrual flow (Lemke and Williams, 2012). These probable pharmacological effects are common to all NSAIDs. NSAIDs may be the most effective when therapy is initiated before the onset of menstrual pain and flow, although, the therapy need not be continued after the end of the flow (Beale and Block, 2011). When NSAIDs are given through the oral route, it causes several side-effects like gastric disturbance, stomach ulcer, nausea, vomiting, etc. (Craig and Stitzel, 2004). Moving toward the pathway of new age technology of drug delivery for overcoming the present problems, transdermal patches are one of the most suitable techniques for reducing the adverse effects, increasing the bioavailability by reducing 
first-pass hepatic metabolism, elevating the permeability of NSAIDs, and facilitating sustained release of drug for the longer duration of time.

Piroxicam is an NSAID utilized for treating dysmenorrhoea in the form of tablet formulation (Mahapatra and Bharti, 2017). As mentioned above, it also suffers from similar adverse effects. To overcome those conditions, the transdermal patch of piroxicam can serve as a better alternative to the tablets which serves as the safe alternative over oral route. In the present research, the transdermal patch of piroxicam was fabricated by using sustained release hydrophilic and lipophilic polymers containing permeation enhancer and thoroughly evaluated.

\section{MATERIALS AND METHODS}

\section{Chemicals}

Piroxicam was received as a generous gift sample from Shree Trading Ltd., Ahmadabad, India. N-octanol, disodium hydrogen phosphate, sodium hydroxide, propylene glycol 400, sodium lauryl sulfate, dichloromethane, and potassium dihydrogen phosphate were procured from Loba Chem Ltd., Mumbai, India. Colorcon Asia Pvt. Ltd., Mumbai, India was the chief supplier for HPMC E15, ethyl cellulose, and polyvinylpyrrolidone (PVP) K30. Methanol was purchased from Himedia Laboratories India, Mumbai, India. All other chemicals and reagents used in the study were of analytical grade.

\section{Evaluation of drug}

Determination of $\lambda_{\max }$

Nearly, $0.1 \mathrm{~g}$ of the drug was dissolved in $100 \mathrm{ml}$ of phosphate buffer ( $\mathrm{pH} 7.4$ ) to prepare $100 \mathrm{mg} / \mathrm{ml}$ of solution. From this solution, $0.1 \mathrm{ml}$ was withdrawn and the volume was made up to $10 \mathrm{ml}$ with phosphate buffer ( $\mathrm{pH}$ 7.4) for preparing the stock solution. The solution containing a concentration of 10 $\mu \mathrm{g} / \mathrm{ml}$ piroxicam was scanned over the wavelength of 200-400 $\mathrm{nm}$ in UV-Vis spectrophotometer to determine the wavelength of maximum absorbance (Nanda et al., 2012).

\section{Determination of partition coefficient}

The two phases (water and n-octanol) were mixed in equal quantities and kept for saturation in separating funnel. The partition coefficient was determined by taking $10 \mathrm{mg}$ of the drug into the solution and shaking them occasionally and the resulting solution was kept on a site for 24 hours. After 24 hours, the two phases were carefully separated in a separating funnel. The aqueous phase was filtered through Whatman filter paper, suitably diluted, and the amount of piroxicam in the aqueous phase was determined by measuring absorbance at $335 \mathrm{~nm}$ using UV-Vis spectrophotometer. The partition coefficient of piroxicam was calculated from the ratio between the concentration of piroxicam in organic and aqueous phases from the below-mentioned formula (Arun, 2014):

$$
\mathrm{K}_{\mathrm{O} / \mathrm{w}}=\frac{\text { Concentration in octanol phase }}{\text { Concentration in aqueous phase }}
$$

\section{Estimation of drug permeability}

The diffusion study was performed using Franz's diffusion cells to determine the permeability of the drug through the barrier. In the experiment protocol, the rat abdominal skin was placed in the receptor compartment and both compartments were held tight by the clamps. The phosphate buffer of $\mathrm{pH} 7.4$ was employed as the receptor solution. The volume of diffusion cell was maintained $6 \mathrm{ml}$ throughout the study and stirring was continued at $100 \mathrm{rpm}$ with the magnetic bead. The temperature of the whole system was maintained at $37^{\circ} \mathrm{C} \pm 1{ }^{\circ} \mathrm{C}$ with the help of the hot plate. The diffusion study was carried out for the period of 12 hours where 1 $\mathrm{ml}$ sample was withdrawn cautiously at every 1 hour interval and analyzed at $335 \mathrm{~nm}$, spectrophotometrically. The same volume of phosphate buffer ( $\mathrm{pH}$ 7.4) was added to the receptor compartment to maintain the sink condition (Patel et al., 2012).

\section{Compatibility study}

The compatibility study of the drug and polymers is an essential requirement before formulating as if the drug will react with the polymers or excipients will lead to a reduced shelf life of the product or may cause unwanted effects on the formulation. The incompatibility between the physical mixture of drug and polymers was determined by Fourier-transformed infrared spectroscopy (FT-IR) spectra and differential scanning calorimetry (DSC) thermogram.

\section{Fourier-transformed infrared (FT-IR) study}

The FT-IR study was performed using $\mathrm{KBr}$ equipped Shimadzu $^{\circledR}$ Affinity-1 FT-IR instrument. The overlapping peaks were identified for the drug, excipients, polymers, and physical mixture. Any new product or major change in the spectra was reported. The peaks were expressed as $\mathrm{cm}^{-1}$ in the range of 4,000-400 $\mathrm{cm}^{-1}$ (Mahajan et al., 2017a).

\section{Differential scanning calorimetry (DSC) study}

The thermal characteristics of the drug (piroxicam), HPMC E15, ethyl cellulose, PVP K30, and physical mixture were studied using the differential scanning calorimeter (Pyris Diamond TG/DTA Perkin Elmer) to determine any incompatibilities, phase formation characteristics, and several inherent properties. The samples (in solid powder form) were weighted and heated in the range of $30^{\circ} \mathrm{C}-300^{\circ} \mathrm{C}$ with a scanning rate of $10^{\circ} \mathrm{C} /$ minutes in an inert atmosphere of nitrogen $(50 \mathrm{ml} /$ minute $)$ in a platinum crucible. The alpha alumina powder served as the reference and calibrated using indium as a standard (Mahajan et al., 2017b).

\section{Steps toward formulation development}

\section{Calculation of flux and drug loading}

The Potts and Guy showed to formulate an empirical relationship between $\mathrm{Kp}$ and two simple characteristics of the permeant; the octanol-water partition coefficient (Koct) and the molecular weight (MW) (Gudalwar et al., 2012).

$$
\begin{aligned}
\log \mathrm{Kp}(\mathrm{cm} / \text { hour })= & -2.72+0.71 \log \text { Koct } \\
& -0.0061 \mathrm{MW}
\end{aligned}
$$

It must be realized that it is not the permeability coefficient alone that determines the efficiency of topical and transdermal delivery. It is the flux across the skin, which is the product of the permeability coefficient and the drug concentration in the vehicle. The maximum achievable flux is, therefore, $\mathrm{Kp}$ multiplied by the aqueous solubility (Sw) (Gudalwar et al., 2012).

$$
\text { Flux }=\log \mathrm{Kp} \times \mathrm{Sw}
$$




\section{Calculation of dose}

From equation (1), the permeability coefficient was computed to be 4.4004 , the determined flux was determined to be $0.101 \mathrm{mg} / \mathrm{cm}^{2} /$ hour, and finally, the dose was fixed to be 12.12 $\mathrm{mg} / 10 \mathrm{~cm}^{2} / 12$ hour. following:

The selection of dose for oral dosage form was based on

- STEP 1: Calculation of permeability coefficient

$$
\begin{aligned}
\log \mathrm{Kp}(\mathrm{cm} / \text { hour })= & -2.72+0.71 \log \text { koct } \\
& -0.0061 \mathrm{MW} \\
\log \mathrm{Kp}(\mathrm{cm} / \text { hour })= & -2.72+(0.71 \times \log 3.12) \\
& -(0.0061 \times 331.35) \\
\log \mathrm{Kp}(\mathrm{cm} / \text { hour })= & 4.4004
\end{aligned}
$$

- STEP 2: Calculation of flux

Flux $=\log \mathrm{Kp} \times \mathrm{SW}$

Flux $=4.4004 \times 0.023$

Flux $=0.101 \mathrm{mg} / \mathrm{cm}^{2} /$ hour

- STEP 3: Calculation of dose for $10 \mathrm{~cm}^{2} / 12$ hour

$$
\begin{aligned}
& \text { Dose }=\text { flux } \times 10 \times 12 \\
& \text { Dose }=0.101 \times 10 \times 12 \\
& \text { Dose }=12.12 \mathrm{mg} / 10 \mathrm{~cm}^{2} / 12 \text { hour }
\end{aligned}
$$

The patches were prepared on the film former. The formula was calculated for the total area of patch spread on the film former:

Area of film spread $=270 \mathrm{~cm}^{2}$

Dose calculated $=12.12 \mathrm{mg} / 10 \mathrm{~cm}^{2}$

Drug load $=270 / 10=27 \times 12.12=327.24 \mathrm{mg} / 270 \mathrm{~cm}^{2}$

All the other ingredients like sodium lauryl sulfate (SLS) and polyethylene glycol (PEG) were calculated accordingly.

\section{Preparation of matrix patch}

The piroxicam matrix transdermal patches were fabricated by the solvent evaporation technique utilizing different ratios of HPMC E15, ethyl cellulose, and PVP K30 (3:1, 3:2, and $2: 1$, respectively. In the process of formulation, initially, the polymer (HPMC K15) was taken in a beaker with a solvent dichloromethane:methanol $(2: 1)$ and was allowed to completely swell for a duration of 1 hour. Subsequently, with continuously stirring, ethyl cellulose was added. Afterward, the plasticizer (PEG 400) and permeation enhancer (SLS) were added and mixed uniformly for the few minutes duration. Finally, the drug (piroxicam) was incorporated with continuous stirring to mix well. The resultant homogenous dispersion was spread over a film former with the help of a dragger. Later, the controlled solvent evaporation was achieved by heating and the fabricated dried film was cut into $10 \mathrm{~cm}^{2}$ dimension. The prepared films were wrapped in aluminum foil and stored in the desiccator for further study (Patel et al., 2013). Table 1 describes the components in formulating the transdermal patches.

\section{Evaluation of transdermal patch}

\section{Weight uniformity}

Aspecified area of the patches was cut carefully in different parts and afterward weighed in a digital balance $\left(\right.$ Shimadzu $^{\circledR}$ AUW220D). The average weight and standard deviation values were calculated from the individual weight (Kumar et al., 2013).
Table 1. Formulation chart for piroxicam transdermal films.

\begin{tabular}{lcccccc}
\hline \multirow{2}{*}{ Ingredients } & F1 & F2 & F3 & F4 & F5 & F6 \\
\cline { 2 - 7 } & $\mathbf{( 3 : 1 )}$ & $\mathbf{( 2 : 1 )}$ & $\mathbf{( 3 : 2 )}$ & $\mathbf{( 3 : 1 )}$ & $\mathbf{( 2 : 1 )}$ & $\mathbf{( 3 : 2 )}$ \\
\hline Piroxicam (in mg) & 327 & 327 & 327 & 327 & 327 & 327 \\
HPMC (in mg) & 3,750 & 3,750 & 3,750 & 3,750 & 3,750 & 3,750 \\
EC (in mg) & 1,250 & 1,875 & 2,500 & - & - & - \\
PVP (in mg) & - & - & - & 1,250 & 1,875 & 2,500 \\
DCM + Methanol & 50 & 50 & 50 & 50 & 50 & 50 \\
(1:2) (in ml) & 1,000 & 1,125 & 1,250 & 1,000 & 1,125 & 1,250 \\
PEG 400 (in mg) & 100 & 112.5 & 125 & 100 & 112.5 & 125 \\
SLS (in mg) & & & & & & \\
\hline
\end{tabular}

\section{Folding endurance}

A patch on the specific area was cut evenly and repeatedly folded at the same place until it was broken. The number of times the film could be folded at the same place without breaking gave the value of the folding endurance (Dey et al., 2011).

\section{Percentage moisture content}

The prepared transdermal films were weighed individually and kept in desiccators containing fused calcium chloride at room temperature for the duration of 24 hours. After 24 hours, the films were re-weighed and the percentage moisture content was determined by the given formula (Darwhekar et al., 2011):

$$
\text { Percentage moisture content }=\frac{\text { Initial weight }- \text { Final weight }}{\text { Final weight }} \times 100
$$

\section{Percentage moisture uptake}

The individually weighed transdermal films were kept in desiccators containing a saturated solution of potassium chloride at room temperature for 24 hours. After 24 hours, the formed piroxicam films were re-weighed and the percentage moisture uptake was measured from the below-mentioned formula (Dahodwala and Sheikh, 2013):

$$
\text { Percentage moisture content }=\frac{\text { Final weight }- \text { Initial weight }}{\text { Initial weight }} \times 100
$$

\section{Drug content determination}

For determining the drug content, an area of $10 \mathrm{~cm}^{2}$ of the patch was cut and dissolved in $10 \mathrm{ml}$ of phosphate buffer $(\mathrm{pH}$ 7.4). After that, $0.1 \mathrm{ml}$ volume was withdrawn from the solution and diluted with the phosphate buffer to $10 \mathrm{ml}$ in a volumetric flask. The absorbances of the solutions were taken at $335 \mathrm{~nm}$ by using UV spectrophotometer (Shimadzu ${ }^{\circledR} \mathrm{UV}$ $1800)$, keeping the pure drug $(0.1 \mathrm{~g})$ as the standard solution (Kumar et al., 2012).

\section{Primary skin irritation study}

For estimating the sensitivity of the formulation toward the skin, the formulated patches were applied to the hairless skin of the albino rats for the duration of 24 hours and the skin inflammation effects were reported for all individual rats (totally six rats used) (Mohamad and Tabassum, 2012). 


\section{In-vitro drug diffusion study}

\section{Preparation of rat skin}

The skin of the rat was utilized for in vitro diffusion studies of the transdermal patch. For the preparation, a healthy Wistar Albino rat was selected and anesthetized with the chloroform. The hair from the abdominal region was shaved carefully with a safety razor and further cleaned with wet cotton to remove the stitched hairs. The rat was sacrificed by the proper method and the hairless clean skin was excised carefully with the help of a surgical blade. The procured skin was then cleaned thoroughly with distilled water and stored in Ringer solution with proper aeration (Singh and Bali, 2016).

\section{In vitro diffusion cell study}

The diffusion study was performed using Franz's diffusion cells to determine the permeability of the drug through the barrier of the fabricated transdermal system. In the experiment protocol, the rat abdominal skin was placed in the receptor compartment and both compartments were held tight by the clamps. The phosphate buffer of $\mathrm{pH} 7.4$ was employed as the receptor solution. The volume of diffusion cell was maintained $6 \mathrm{ml}$ throughout the study and stirring was continued at $100 \mathrm{rpm}$ with the magnetic bead. The temperature of the whole system was maintained at $37^{\circ} \mathrm{C} \pm 1^{\circ} \mathrm{C}$ with the help of the hot plate. The diffusion study was carried out for the period of 12 hours where 1 $\mathrm{ml}$ sample was withdrawn cautiously at every 1 hour interval and analyzed at $335 \mathrm{~nm}$, spectrophotometrically. The same volume of phosphate buffer ( $\mathrm{pH}$ 7.4) was added to the receptor compartment to maintain the sink condition (Patel et al., 2012).

\section{RESULTS AND DISCUSSION}

The $\lambda_{\text {max }}$ of the drug was found to be $335 \mathrm{~nm}$. The drug piroxicam exhibited partition coefficient value of 3.12 based on octanol:water system. The results indicated that the lipophilic nature of drug fulfills the criteria for formulating it into a transdermal patch. The calibration curve of the drug displayed a high linearity with an $r^{2}$ value of 0.995 where a linear relationship was observed within the concentration range. The permeability of piroxicam after 12 hours duration was determined to be $26.65 \%$.

The piroxicam transdermal patches were fabricated by the solvent evaporation technique with an aim to improve the bioavailability of piroxicam. The fabricated film was found to be uniform, flexible, smooth, and transparent. The weight of the formed transdermal patches of different formulations was in the range of $143.9 \pm 2.12 \mathrm{mg}$ and $218.2 \pm 2.23 \mathrm{mg}$. The thickness of the patches of different formulations ranged from $0.061 \pm 0.0019$ $\mathrm{mm}$ to $0.077 \pm 0.0013 \mathrm{~mm}$. The thickness of the transdermal patches was found to be proportional to the concentration of the polymers. The value of low standard deviation represented that the preparation of transdermal formulation is quite reproducible with similar weight and thickness. All the fabricated films were evaluated for their physical parameters (weight, thickness, folding endurance, diameter, and in vitro diffusion).

\section{Compatibility study}

There was no incompatibility observed between the drug, excipients, and polymers as indicated by the FT-IR and DSC studies. The FT-IR spectra demonstrated the presence of characteristic peaks of drugs and polymers. The chief peaks of the drug were $3,450,3,066,2,931,2,521,1,745$, and $1,629 \mathrm{~cm}^{-1}$ and for polymers 3,473, 2,974, 2,922, 2,611, 2,430, 1,639, 1,629, 1,529, 1,460, and $1,425 \mathrm{~cm}^{-1}$ (Fig. 1), respectively. The physical mixture exhibited distinctive drug peaks in the spectra along with the polymer peaks, confirming that the drug remains in inert form with the excipients. Additionally, the DSC thermogram of piroxicam displayed a sharp endothermic peak at $203.95^{\circ} \mathrm{C}$ (Fig. 2A) which corresponds with the melting point of the drug, thus proving the sample genuine. Similarly, the thermograms of polymers HPMC E15, ethyl cellulose, and PVP K30 exhibited endothermic peaks at
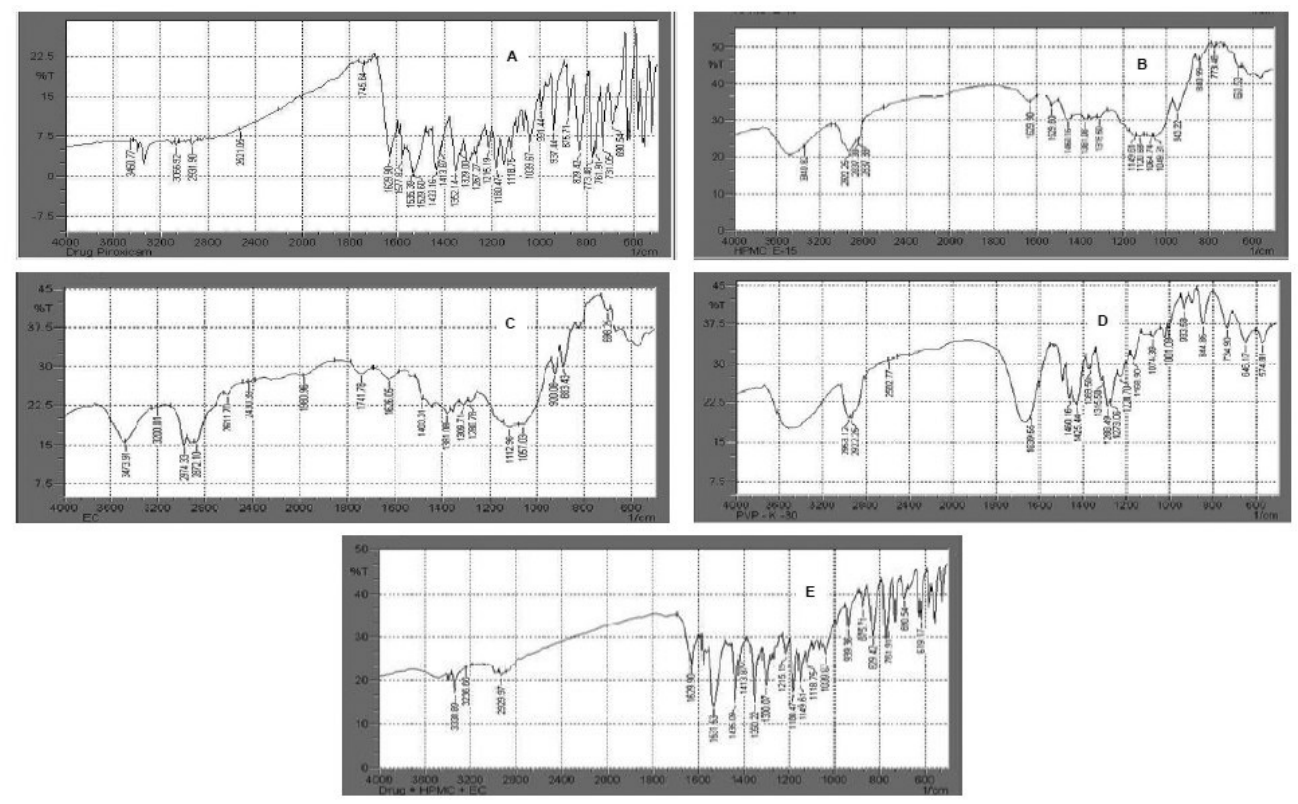

Figure 1. FT-IR spectra: (A) piroxicam; (B) HPMC E15; (C) ethyl cellulose; and (D) PVP K30; (E) physical mixture. 
$112.35^{\circ} \mathrm{C}$ (Fig. 2B), $160.12^{\circ} \mathrm{C}$ (Fig. 2C), and $180.25^{\circ} \mathrm{C}$ (Fig. 2D), respectively. While studying both the physical mixtures; piroxicam + HPMC E15 + Ethyl cellulose (Fig. 2E) and piroxicam + HPMC E15 + PVP K30 (Fig. 2F), the thermogram revealed specific endothermic peaks as shown individually by the ingredients. Therefore, from both the above studies, it can be concluded that there is no interaction between the polymers and the drug.

\section{Evaluation of transdermal patch}

The films exhibited an excellent weight uniformity among the various fabricated batches. The uniformity of weight indicates that the polymer solution of the drug is well dispersed on a flat surface. However, a little variation in weight among the formulation F1-F6 was observed in the range of 41-82 $\mathrm{mg}$ which may attribute to the variation in polymeric content (Table 2). An increase in the weight of the fabricated formulation (F1-F3) was seen with an increase in the $\mathrm{EC}$ concentration. This may be due to the fact that $\mathrm{EC}$ is having a low water permeability nature that prevents water evaporation and hence retains the mass considerably (Patil et al., 2016). The batch F5 (2:1 ratio) demonstrated the highest weight variability of $85 \mathrm{mg}$ while the batch $\mathrm{F} 1$ exhibited the lowest weight variability of $41 \mathrm{mg}$.
All formulations exhibited a slight variation in drug content ranging from $89.16 \%$ to $95.04 \%$ (Table 2). Formulation F1 shows the highest drug content of $95.04 \%$ while the batch F4 presented the lowest drug content of $89.16 \%$. All formulations found to be satisfactory with reference to the drug content.

The $\%$ moisture content was found to be in the range of $1.23 \%-3.16 \%$ in the formulation F1-F6 (Fig. 3). With the increase in the polymer concentration (HPMC, EC, and PVP), the content of moisture was observed to escalate. Small moisture content in the formulation helps them to remain stable and prevent from being a completely dried and brittle. It has been observed that the optimized ratio of $2: 1$ for HPMC:EC/PVP leads to an increased retention of moisture to the formulation. The high ratios of hydrophilic concentration in $\mathrm{F} 2$ resulted in increased \% moisture preservation (Table 2). The moisture uptake rate was found to be in the range of $1.32 \%-2.64 \%$. A low moisture uptake protects the material from microbial contamination and bulkiness of the patch. The formulations F1 and F4 displayed the lowest moisture absorption attributes as a result of the decrease in water permeability of the polymer ethyl cellulose (Godbole et al., 2017). The absorption of moisture is an imperative aspect which
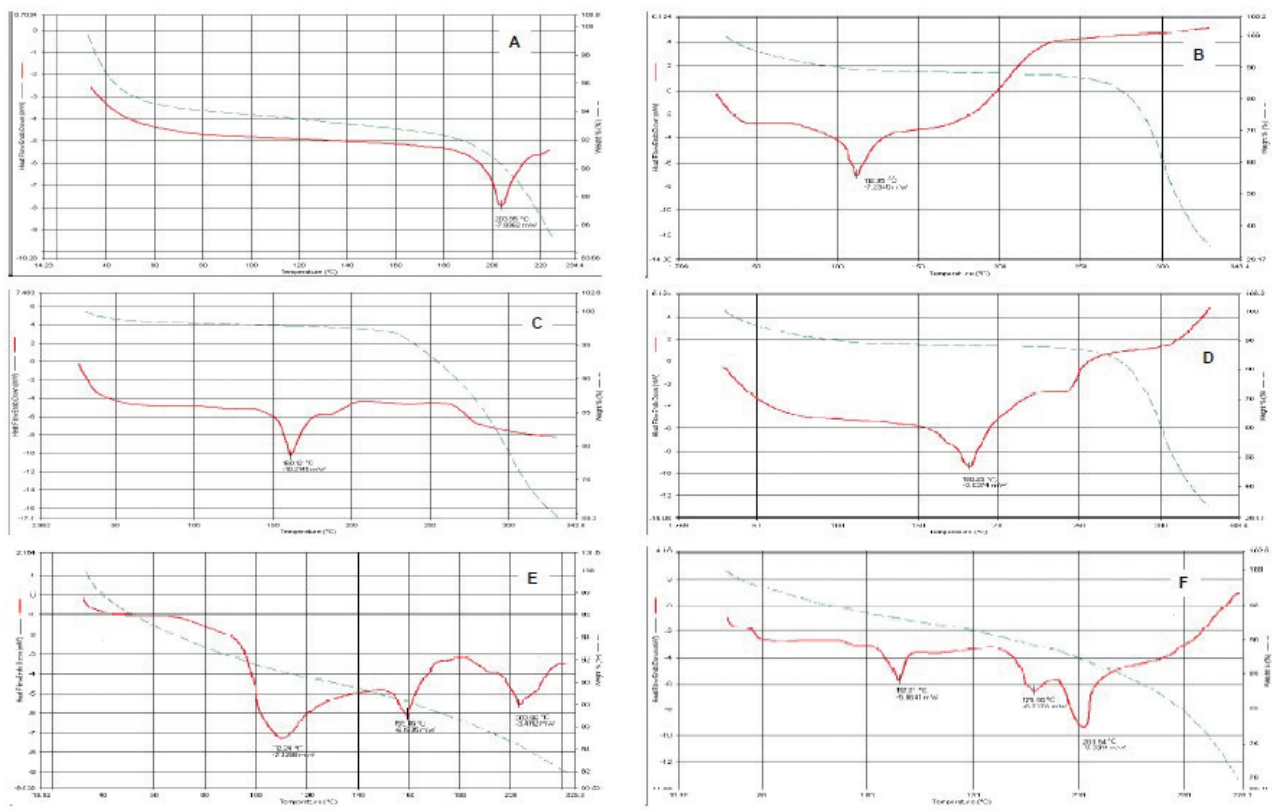

Figure 2. DSC thermogram: (A) piroxicam; (B) HPMC E15; (C) ethyl cellulose; (D) PVP K30; (E) piroxicam + HPMC E15 + ethyl cellulose; and (F) piroxicam + HPMC E15 + PVP K30.

Table 2. Evaluation characteristics of piroxicam transdermal films.

\begin{tabular}{ccccccc}
\hline Formulations & $\begin{array}{c}\text { Weight uniformity } \\
\text { (in mg) }\end{array}$ & \% Drug content & \% Moisture content & \% Moisture uptake & Folding endurance & Skin irritancy \\
\hline F1 & 41 & 95.04 & 2.41 & 1.32 & 1.51 & No irritation \\
F2 & 53.3 & 94.48 & 3.16 & 1.54 & No irritation \\
F3 & 43.3 & 91.84 & 2.21 & 2.15 & 99 \\
F4 & 68 & 89.16 & 1.73 & 2.19 & 101 & No irritation \\
F5 & 82 & 94.27 & 1.89 & 2.64 & 105 & No irritation \\
F6 & 63 & 94.38 & 1.23 & No irritation \\
\hline
\end{tabular}




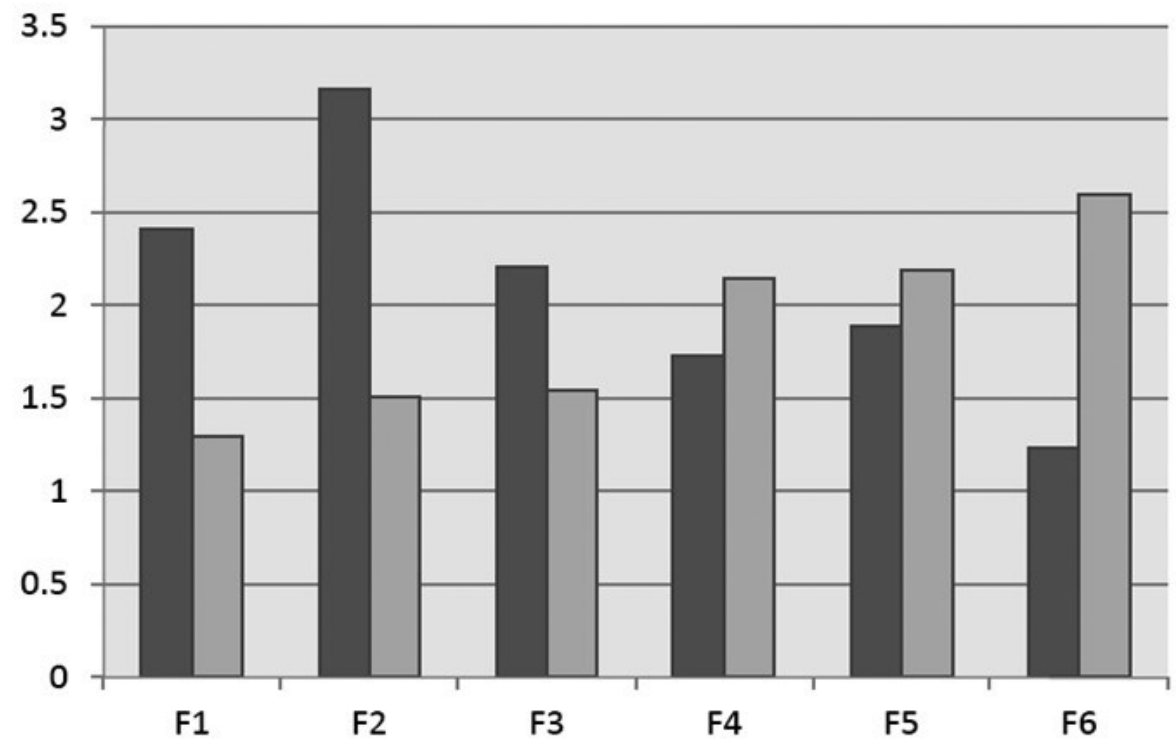

$\%$ moisture content $\square \%$ moisture uptake

Figure 3. $\%$ moisture content and $\%$ moisture uptake by the fabricated transdermal formulations.

influences the drug diffusion as it extends into the water uptake of the patch from the body tissues as well as from the environment during the application period. It is a vital parameter which helps to maintain the mechanical integrity.

The folding endurance was found out manually in order to determine the plasticity of the prepared patch. The number of times the film could be folded at the same place without breaking gave the value of folding endurance. The folding endurance was satisfactory in all the batches (99-125). In comparing the batches, it was seen that the formulations F2 and F1 containing HPMC:EC/PVP of 2:1 demonstrated better folding endurance of 125 and 112 than the batches F3 and F4 which presented folding endurance of 99 and 101, respectively (Table 2). The batches F5 and F6 had the satisfactory folding endurance of 105 and 103, respectively. The increased concentration of hydrophilic polymers in the formulation greatly affected the folding endurance as it provided better elasticity.

After 24 hours, no inflammation of the skin was observed in all the formulations. Hence, all the prepared formulations passed the skin irritation test (Table 2).

\section{In vitro diffusion study}

The diffusion studies of patches containing different permeation enhancer SLS (F1-F6) were carried out to observe the diffusion of the drug from the patches. As compared with other formulations, F1 shows the highest percentage of drug diffuse (91.04\%), whereas lowest drug release was expressed by the batch F4 (84.66\%) at the end of 12 hours (Table 3). There was no significant variation in the drug permeation values among all the formulations. However, the cumulative amount of drug released from formulations F1 (84.66\%), F2 (89.34\%), F5 (90.99\%), and F6 $(90.46 \%)$ was considerably higher than that of formulations F3 $(86.64 \%)$ and F4 (84.66\%). The diffusion rate was scrutinized in the following pattern: $\mathrm{F} 1>\mathrm{F} 5>\mathrm{F} 6>\mathrm{F} 2>\mathrm{F} 3>\mathrm{F} 4$. In addition to the nature of the polymer, the concentration of polymer also affects the drug release. As the concentration of polymer increased, the drug release gets decreased (Umaredkar et al., 2018). One of the most likely reasons that can be considered for the highest diffusion of the drug from formulation F1 was the concentration of hydrophilic polymer and hydrophobic polymer. Higher concentration of these two polymers (HPMC and EC); it forms a strong viscous gel on contact with the aqueous media that hinders the diffusion of the drug from the formulation (Dangre et al., 2016). Therefore, it has been detected that the formulations F3 and F2 demonstrated less in vitro drug diffusion as compared with formulation $\mathrm{F} 1$ at 12 hours. In contrast, the formulations F4-F6, containing polymer PVP, the drug diffusion was observed to be non-consistent in nature where the diffusion did not follow any linearity and a phenomenon of polymer concentration-dependent release was not seen during the 12 hours of the study. The formulation F5 and F6 presented a good in vitro drug release from the patch due to the burst effect of PVP and also more solubility in aqueous media.

Table 3. In-vitro drug diffusion from various formulations of transdermal patches.

\begin{tabular}{ccccccc}
\hline \multirow{2}{*}{$\begin{array}{c}\text { Time } \\
\text { (hours) }\end{array}$} & \multicolumn{6}{c}{ \% Cumulative drug release } \\
\cline { 2 - 7 } & F1 & F2 & F3 & F4 & F5 & F6 \\
\hline 1 & 26.21 & 22.98 & 17.72 & 30.99 & 30.36 & 34.04 \\
2 & 36.10 & 35.66 & 34.76 & 35.65 & 33.20 & 35.06 \\
3 & 41.87 & 36.06 & 37.93 & 36.35 & 35.89 & 36.02 \\
4 & 43.33 & 36.35 & 41.37 & 37.31 & 36.14 & 38.69 \\
5 & 45.05 & 41.66 & 42.89 & 43.06 & 49.41 & 46.05 \\
6 & 49.95 & 51.29 & 53.32 & 49.39 & 51.92 & 50.81 \\
7 & 56.17 & 56.40 & 57.92 & 56.06 & 58.53 & 59.69 \\
8 & 64.64 & 62.95 & 64.82 & 62.20 & 63.29 & 64.58 \\
9 & 74.63 & 72.69 & 69.96 & 65.15 & 71.21 & 71.33 \\
10 & 81.33 & 80.46 & 75.56 & 75.38 & 88.51 & 86.44 \\
11 & 86.23 & 82.44 & 81.41 & 81.23 & 89.17 & 87.46 \\
12 & 91.04 & 89.34 & 86.64 & 84.66 & 90.99 & 90.46 \\
\hline
\end{tabular}




\section{CONCLUSION}

Dysmenorrhoea treatment demands prolonged and sustained plasma levels of the drug which ultimately depends upon the release pattern of a drug from transdermal patch. In this study, the mixture of HPMC K15, PVP, and EC was found to be completely compatible with the drug molecule and the designed formulation release the drug in a sustained fashion over a prolonged period of time. The transdermal patches of piroxicam were prepared using the combination of polymers, HPMC, PVP, and EC in different concentration with SLS as the permeation enhancer and polyethylene glycol 400 as the plasticizer were used for the formulation of transdermal drug delivery system which demonstrated sustained release of drug through the patches. The formulation F1 showed a maximum release and permeation of drug for a longer time period up to 12 hours. In a thorough study of the evaluation parameters, the highly optimized parameters were observed for the formulation F2. However, the F1 formulation containing hydrophilic and lipophilic polymers (3:1 ratio) was suitable for the development of sustained release patches of piroxicam. Hence, it can be concluded that piroxicam can be successfully formulated as the transdermal patch that can release the drug for an extended period of time up to 12 hours in a sustained manner. Such a drug delivery system can be used to avoid the side effects associated with the therapy and can safely deliver the drug for treating dysmenorrhoea with better patient compliance.

\section{REFERENCES}

Arun R. Formulation evaluation and in vitro permeation studies of transdermal nifedipine from matrix types patches. Int J Pharm Pharm Sci, 2014; 6(1):185-88

Beale JM, Block JH. Wilson and Gisvold's textbook of organic medicinal and pharmaceutical chemistry. Lippincott Williams \& Wilkins, Philadelphia, PA, 2011.

Brunton L, Parker K, Blumenthal D, Buxton I. Goodman \& Gilman's manual of pharmacology and therapeutics. The McGraw-Hill, New York, NY, 2008.

Colledge NR, Walker BR, Ralston SH. Davidson's principles and practice of medicine. Elsevier, New York, NY, 2010.

Craig CR, Stitzel RE. Modern pharmacology with clinical applications. Lippincott Williams \& Wilkins, Philadelphia, PA, 2004.

Dahodwala ST, Sheikh A. Formulation and evaluation of transdermal film of promethazine hydrochloride. J Adv Pharm Edu Res, 2013; 3(4):559-65.

Dangre PV, Godbole MD, Ingale PV, Mahapatra DK. Improved dissolution and bioavailability of eprosartan mesylate formulated as solid dispersions using conventional methods. Indian J Pharm Edu Res, 2016; 50(3):S209-17.

Darwhekar G, Jain DK, Patidar VK. Formulation and evaluation of of clopidogrel bisulfate. Asian J Pharm Life Sci, 2011; 1(3):269-78.

Dey SK, De PK, Sen T, Shankar V, Banerjee U. Formulation and in vitro evaluation of transdermal matrix patches of diclofenac sodium. J Pharm Res, 2011; 4(10):3593-6.

Godbole MD, Mahapatra DK, Khode PD. Fabrication and characterization of edible jelly formulation of stevioside: a nutraceutical or OTC aid for the diabetic patients. Inventi Nutraceut, 2017; 2017(2):1-9.
Gudalwar BR, Borkar VK, Sonkamble MK, Khalkar SG, Jadhav JK. Development of bilayered transdermal patches of ondansetron hydrochloride: physicochemical and ex vivo characterization. Int J Pharma World Res, 2012; 3(2):1-22.

Kumar SS, Behury B, Sachinkumar P. Formulation and evaluation of transdermal patch of Stavudine. Dhaka Univ J Pharm Sci, 2013; 12(1):63-9.

Kumar SR, Jain A, Nayak S. Development and evaluation of transdermal patches of colchicine. Der Pharm Lett, 2012; 4(1):330-43.

Kumar V, Cotran RS, Robbins SL. Basic pathology. W B Saunders Company, Philadelphia, PA, 1992.

Lemke TL, Williams DA. Foye's principles of medicinal chemistry. Lippincott Williams \& Wilkins, Philadelphia, PA, 2012.

Mahajan NM, Pardeshi A, Mahapatra DK, Darode A, Dumore NG. Hypromellose and Carbomer induce bioadhesion of Acyclovir tablet to vaginal mucosa. Indo Am J Pharm Res, 2017a; 7(12):1108-18.

Mahajan NM, Wadhwane P, Mahapatra DK. Rational designing of sustained release matrix formulation of etodolac employing hypromellose, carbomer, eudragit and povidone. Int J Pharm Pharm Sci, 2017b; 9(12):92-7.

Mahapatra DK, Bharti SK. Handbook of research on medicinal chemistry: innovations and methodologies. 1st edition, Apple Academic Press, New Jersey, 2017.

Mohamad M, Tabassum N, Ali J, Jan R. Preparation and evaluation of transdermal patch of aceclofenac. J Pharm Res, 2012; $5(1): 331-2$

Nanda S, Saroha K, Yadav B, Sharma B. Formulation and characterization of transdermal patch of amlodipine besylate. Int J Pharm Chem Sci, 2012; 1(3):953-69.

Patel KN, Patel HK, Patel VA. Formulation and characterization of drug in adhesive transdermal patches of diclofenac acid. Int J Pharm Pharm Sci, 2012; 4(1):296-9.

Patel MP, Gupta MM. Formulation development and evaluation of transdermal patch of anti-diabetic drug pioglitazone. Pharm Innov, 2013; $2: 80-8$.

Patil MD, Mahapatra DK, Dangre PV. Formulation and in-vitro evaluation of once-daily sustained release matrix tablet of nifedipine using rate retardant polymers. Inventi Impact Pharm Tech, $2016 ; 4: 190-6$.

Singh A, Bali A. Formulation and characterization of transdermal patches for controlled delivery of duloxetine hydrochloride. J Anal Sci Technol, 2016; 7(1):25.

Umaredkar AA, Dangre PV, Mahapatra DK, Dhabarde DM. Fabrication of chitosan-alginate polyelectrolyte complexed hydrogel for controlled release of cilnidipine: a statistical design approach. Mater Technol, 2018:1-1.

\section{How to cite this article:}

Mahajan NM, Zode GH, Mahapatra DK, Thakre S, Dumore N, Gangane PS. Formulation development and evaluation of transdermal patch of piroxicam for treating dysmenorrhoea. J Appl Pharm Sci, 2018; 8(11): 035-041. 